\title{
Muskelrelakserende midler
}

\author{
Sammendrag \\ Bakgrunn. Muskelrelakserende midler \\ ble første gang brukt i organisert anes- \\ tesisammenheng i 1942. Hensikten \\ med denne artikkelen er å gjøre rede \\ for medikamentgruppens virkemåte, \\ historikk og plass i dagens anestesi- \\ virksomhet.
}

\section{Materiale og metode. Oversikten er basert på klinisk erfaring, egen forsk- ning og ikke-systematisk litteratursøk i PubMed.}

\section{Resultater. Et muskelrelakserende middel er enten ett av mange curare- stoffer eller suksametonium (Curacit). Curare ble brakt til Europa på 1700-tal- let. I 1935 ble det aktive stoffet isolert. Muskelrelakserende midler virker lammende ved å konkurrere med ace- tylkolin om binding til de reseptorene som er involvert i signaloverføringen mellom nerve og tverrstripet viljestyrt muskel. Det unike med disse midlene er at optimal muskelrelaksasjon under anestesiologisk og kirurgisk virksom- het kan oppnås uten at man må gi høye doser av anestesimidler. Muskelrelak- serende midler er imidlertid ikke anes- tetika, de påvirker ikke bevisstheten og har ingen smertestillende effekt. En muskelrelaksans som virker opti- malt i alle kliniske sammenhenger, er foreløpig ikke utviklet.}

Fortolkning. Muskelrelakserende midler er generelt trygge når de blir brukt korrekt, men særlig suksametonium kan ha enkelte alvorlige bivirkninger. Bruken av muskelrelakserende midler er imidlertid blitt mindre i de senere år, fordi man i dag ofte kan anvende anestesiologiske teknikker som utnytter den muskelrelakserende effekten av moderne anestetika og opioider.

\section{Tom Heier}

tom.heier@medisin.uio.no

Avdeling for anestesi

Oslo universitetssykehus, Aker

0514 Oslo

Tradisjonelt inndeles muskelrelakserende midler $\mathrm{i}$ to grupper ut fra forskjellige virkningsmekanismer - de egentlige curarestoffene og suksametonium. Midlene lammer all viljestyrt tverrstripet muskulatur hvis medikamentkonsentrasjonen i blodbanen blir høy nok.

I denne artikkelen gjøres det rede for virkemåte, historikk og midlenes rolle $\mathrm{i}$ dagens anestesi.

\section{Materiale og metode}

Klinisk erfaring, egen forskning og et ikkesystematisk litteratursøk i PubMed er bakgrunn for denne oversiktsartikkelen.

\section{Muskelrelakserende midlers plass i klinisk anestesi}

Disse midlene ble introdusert i medisinen lenge før anestesi ble en medisinsk spesialitet, men i dag er det innen dette fagfeltet medikamenttypen først og fremst brukes. De inngår som en integrert del av gjennomføringen av svært mange anestesier. Anestesøren har da optimale forhold for endotrakeal intubasjon uten å måtte bruke høye doser anestetika (sedativer med og uten opioider). I øyeblikkelig hjelp-situasjoner, da man trenger rask og pålitelig kontroll over luftveiene, er bruk av muskelrelakserende midler spesielt viktig.

Kirurgen kan også ha stor nytte av muskelrelaksasjon fordi muskelspenninger til tider vanskeliggjør det kirurgiske arbeidet. I visse situasjoner (f.eks. ved enkelte inngrep innen nevro- og øyekirurgi) må man unngå selv små reflektoriske muskulære avvergereaksjoner. Dyp muskelblokade hindrer dette. Bruken av muskelrelakserende midler er imidlertid blitt redusert i de senere år fordi man i dag ofte kan anvende anestesiologiske teknikker som utnytter den muskelrelakserende effekten av moderne anestetika og opioider.

\section{Virkningsmekanisme}

Normal impulsledning i motoriske nervefibre fører til frigjøring av acetylkolin fra nerveendene. Frigjort acetylkolin binder seg til acetylkolinreseptorer på nerveendene selv (presynaptisk binding) og på muskelcellens såkalte endeplate (postsynaptisk binding) (fig 1) (1). Presynaptisk binding gir positiv feedback til nerveenden slik at acetylkolinproduksjonen øker. Dermed unngår muskulaturen tretthet over en rimelig tidsperiode. Postsynaptisk binding av acetylkolin medfører depolarisering av endeplaten (to acetylkolinmolekyler er nødvendig), det vil si at reseptoren endrer konfigurasjon og blir til en ionekanal som slipper natrium og kalsium inn i muskelcellen. Et muskelaksjonspotensial og en muskelkontraksjon oppstår hvis tilstrekkelig antall reseptorer blir aktivert (5-30\%). En acetylkolinesterase finnes også på endeplaten (fig 1) og bryter ned acetylkolinet i løpet av $<1$ msek. Da vil ionekanalen lukke seg og muskelcellens hvilemembranpotensial gjenopprettes. Denne normaliseringen av membranpotensialet er helt nødvendig for at muskelcellen skal bli i stand til å reagere på neste ladning med acetylkolin som eventuelt måtte bli frigjort fra nervecellen.

Muskelrelakserende midler blokkerer funksjonen i viljestyrt tverrstripet muskulatur ved å konkurrere med acetylkolinet om binding til pre- og postsynaptiske acetylkolinreseptorer. De egentlige curarestoffene gir opphav til en såkalt ikke-depolariserende blokkering, fordi deres reseptorbinding hindrer at reseptorene kan rekonfigureres til ionekanaler. Kun ett molekyl av et muskelrelakserende stoff er nødvendig for å oppnå blokade av en reseptor. For å hindre at frigjort acetylkolin fører til muskelkontraksjon må imidlertid medikamentkonsentrasjonen $\mathrm{i}$ synapsen være så høy at 70-95\% (relativt store variasjoner mellom de enkelte muskelceller) av acetylkolinreseptorene på endeplaten blokkeres (2). Når curarestoffet diffunderer vekk fra synapsen fordi plasma-

\section{Hovedbudskap}

- Bruk av muskelrelakserende midler inngår som en integrert del av dagens anestesiologiske praksis

- Muskelrelakserende midler konkurrerer med acetylkolin om plass på nerve-muskel-overgangens preog postsynaptiske reseptorer

- Frekvensen av alvorlige bivirkninger ved bruk av muskelrelakserende midler er lav 
konsentrasjonen begynner å falle, vil etter hvert mengden frigjort acetylkolin bli stor nok til at endeplaten igjen kan depolariseres og den presynaptiske feedbackmekanismen kan gjenoppta sin funksjon.

Den presynaptiske effekten av curaremidler kan greit følges under klinisk anestesi ved at man for eksempel registrerer kraften i tommelfingerbevegelsen når $\mathrm{n}$. ulnaris stimuleres elektrisk med lav strømstyrke. Stor grad av trettbarhet (pga. inhibisjon av den presynaptiske positive feedbackmekanismen) i tommelkraften ved repetert nervestimulering betyr at det fortsatt foreligger betydelig curareeffekt.

Suksametonium virker primært postsynaptisk. Stoffet består av to acetylkolinmolekyler som er satt sammen og depolariserer prinsipielt endeplaten på samme måte som acetylkolin. Hos de fleste pasienter kan forbigående ukoordinerte muskelrykninger i mange muskelgrupper observeres når effekten av medikamentet inntrer. Imidlertid klarer ikke acetylkolinesterasen å bryte ned suksametonium, og stoffet blir derfor værende på reseptorene i kortere eller lengre tid, inntil plasmakonsentrasjonen synker til et lavere nivå enn den i synapsen mellom nerve og muskelcelle. Suksametonium gir en såkalt depolariserende blokkering fordi den vedvarende bindingen til reseptoren hindrer normalisering av muskelcellens membranpotensial (ionekanalen lukker seg ikke) etter den initiale depolariseringen av endeplaten (3).

\section{Historisk tilbakeblikk}

«Curare» kommer av «woorari» eller «ourari», som de innfødte i Sør-Amerika benevnte pilgiften de brukte for å drepe sitt bytte. Ofrene døde av kvelning fordi respirasjonsmuskulaturen ble lammet. Curaren inneholdt ekstrakter fra mange forskjellige planter, og de enkelte indianske stammene hadde hver $\sin$ resept for fremstillingen. Den vestlige sivilisasjon fikk høre om det muskellammende stoffet på 1500-tallet da forskjellige europeiske land kjempet om hegemoniet i Sør-Amerika. Franskmannen Charles Marie de la Condamine er kjent for å ha brakt curare til Europa (i 1745). Curare var opprinnelig tilgjengelig $i$ tre forskjellige former, avhengig av hvordan giften ble opppbevart: «tube curare» (bambusrør), «gourd curare» (squashskall) og «pot curare» (leirkrukker). Senere ble det klart at det aktive stoffet også var forskjellig i de tre formene (hhv. d-tubokurarin, alloferin/toksiferin, protokurarin/protokuridin). Mest kjent ble «tube curare».

Dyreeksperimenter på 1700-tallet viste at primæreffekten gikk på muskelfunksjonen fordi hjertet slo lenge etter at pusteevnen hadde opphørt. I 1811 gjorde den engelske kirurgen Benjamin Collins Brodie et svært viktig forsøk med curare og etablerte dermed samtidig konseptet kunstig ventilasjon i medisinen. Han lammet respirasjonen til en katt med midlet, men holdt liv i dyret ved å

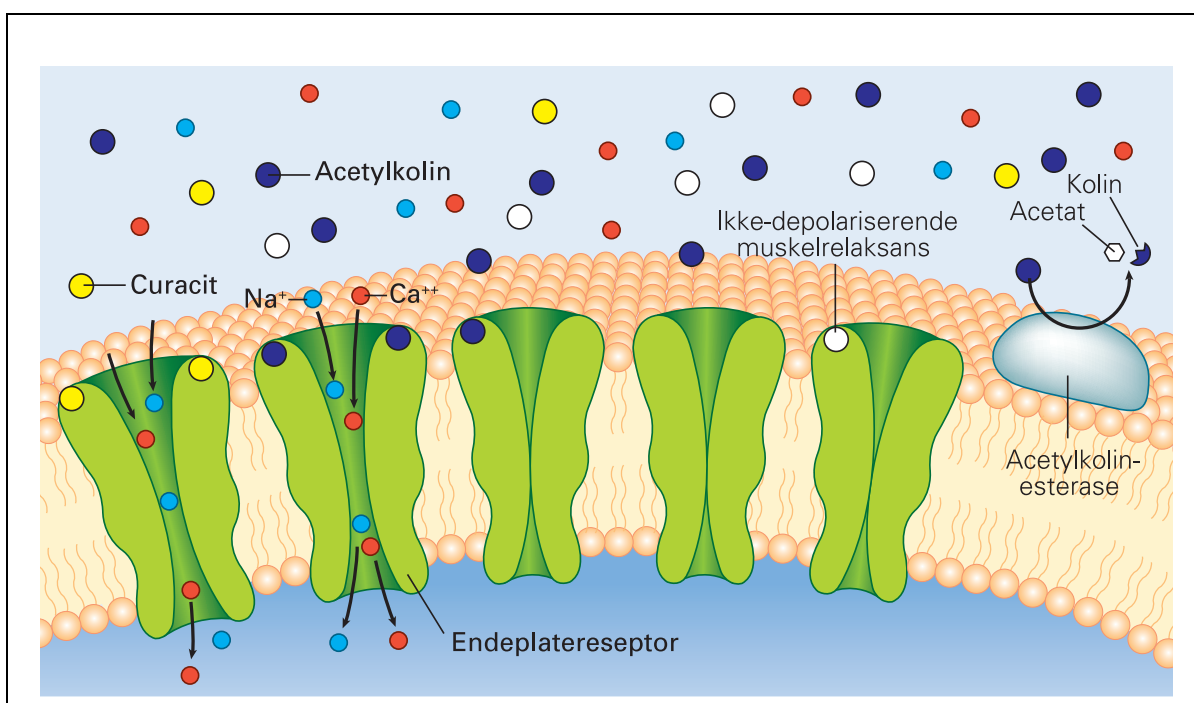

Figur 1 Virkningene av acetylkolin og curarestoffer på den motoriske endeplate. Hvis endeplatereseptoren binder to acetylkolinmolekyler samtidig, endres den til en ionekanal som slipper $\mathrm{Na}+$ og $\mathrm{Ca}++$ inn i cellen. Hvis et tilstrekkelig antall reseptorer åpner seg, depolariseres endeplaten til over en terskelverdi, og en muskelkontraksjon oppstår. Binding av ett curaremolekyl til én reseptor er tilstrekkelig til å hindre konfigurasjonsendringen til en ionekanal. Normalt må 70 - $95 \%$ av endeplatens reseptorer være blokkert av et curarestoff for å hindre at frigjort acetylkolin etter en nerveimpuls fører til en muskelkontraksjon. En acetylkolinesterase er bundet til endeplaten og bryter effektivt ned frigjort acetylkolin. Hvis ikke acetylkolinet fjernes fra reseptoren, vil depolariseringen av endeplaten vedvare og lammelse av muskelcellen oppstå. Suksametonium åpner ionekanalen på tilsvarende vis som acetylkolin, men holder kanalen åpen lenger fordi acetylkolinesterasen ikke bryter stoffet ned

blåse luft inn gjennom en trakeostomi (4). I 1850 publiserte Claude Bernard resultatene fra sine berømte curareforsøk (5). Han viste at ekstremitetsmuskulaturen var mer følsom for stoffet enn diafragma, at sensoriske nerver ikke var affisert, og at både isjiasnerven og $\mathrm{m}$. gastrocnemius beholdt sine respektive funksjoner under pågående curareeffekt. Angrepspunktet for giften måtte derfor ligge på overgangen mellom nerve og muskel.

I 1936 viste sir Henry Hallett Dale (nobelprisen i fysiologi eller medisin i 1936) at acetylkolin var transmitter på nerve-muskel-overgangen (6) og at denne funksjonen kunne hemmes av curare. Den endelige sannhet om curare forble imidlertid et mysterium helt frem til 1935, da kjemikeren Harold King i Dales laboratorium klarte å isolere det aktive stoffet i rørcurare, et bensylisokinolinalkaloid (organisk molekyl som inneholder oksygen og nitrogen) med ikke-depolariserende virkning på nerve-muskel-overgangen (7). Han kalte substansen tubokurarin, fordi denne curaren opprinnelig ble lagret i bambusrør. Han viste også at det var d-isomeren av stoffet som var aktiv (derav navnet d-tubokurarin).

I slutten av 1930-årene ble Intocostrin lansert for kommersiell bruk, basert på fysiologisk fremstilt d-tubokurarin fra regnskogsplanten Chondrodendron tomentosum. Intocostrin ble først brukt til psykiatriske pasienter for å mildne kramper indusert av det antidepressive midlet metrazol. Arthur Lawen i Leipzig eksperimenterte med å gi curare intramuskulært til anesteserte pasienter så tidlig som i 1912. Likevel er det en vanlig oppfatning at curare første gang ble brukt i anestesisammenheng i 1942, da Griffith \& Johnsen i Montreal brukte d-tubokurarin til en serie på 25 pasienter anestesert med cyklopropan (8).

Man ble raskt klar over at curare hadde et betydelig bruksområde - man kunne nemlig oppnå god muskelrelaksasjon under inngrep $i$ thorax og abdomen uten bruk av svært store doser med anestesimidler. Frem til rundt 1960 anesteserte man nemlig med eter og cyklopropan, medikamenter som i store doser kunne ha betydelige sirkulatoriske bivirkninger. Initialt var imidlertid motstanden mot innføring av curare i anestesien likevel stor, og i 1954 rapporterte Beecher \& Todd at mortaliteten i tilslutning til kirurgi var seks ganger høyere hvis curare ble brukt under inngrepet (9). Dette skyldtes i stor utstrekning respirasjonssvikt, fordi det fortsatt var nokså uvanlig å sikre luftveier og ventilasjon ved hjelp av trakealintubasjon, selv ved store inngrep. Man forsøkte isteden å gi så lite curare at diafragma ikke ble lammet fullstendig. Etter at trakealintubasjon ble vanlig (oral trakealintubasjon hos mennesker ble gjort første gang av den engelske kirurgen McEwan i 1878), var det ingen forskjell i dødelighet mellom inngrep med og inngrep uten anvendelse av curare.

Lenge trodde man at curare også var et anestetikum, og så sent som i 1945 ble pasienters erfaringer med kirurgisk behandling under full muskellammelse uten analgetika eller vesentlig sedasjon rapportert (10). Pasientene beskrev full våkenhet under inngre- 
pet og uutholdelige smerter samtidig som de var ute av stand til å gi til kjenne at de var våkne. Derfor ble det $\mathrm{i}$ en lederartikkel i The Lancet samme år gitt en klar advarsel til dem som ville bruke curare under anestesi: «Care must therefore be taken to deaden sensation and ensure unconsciousness.»

I løpet av 1950-årene økte bruken av d-tubokurarin betydelig, men histaminfrigjøring og mulighet for betydelig blodtrykksfall pga. ganglieblokkerende effekter gjorde at det tidlig ble startet forskning for å finne alternativer. Daniele Bovet, en italiensk farmakolog som fikk nobelprisen i fysiologi eller medisin i 1957, var her foregangsmann. I denne sammenhengen ble suksametonium (Curacit) lansert som den ideelle muskelrelaksans i 1950. Det ble imidlertid raskt klart at medikamentet kunne ha alvorlige bivirkninger. Derfor hadde d-tubokurarin en dominerende plass til godt ut i 1960-årene, da det i stor utstrekning ble avløst av pankuronium, et syntetisk fremstilt alkaloid med steroidstruktur. Pankuronium hadde færre og langt mindre alvorlige kardiale bivirkninger enn det opprinnelige curarepreparatet. På grunn av den lange virketiden og manglende fleksibilitet $\mathrm{i}$ forbindelse med korte kirurgisk inngrep ble pankuronium i 1980årene avløst av vekuronium (steroid) og atrakurium (isokinolin). De nye preparatene hadde mye kortere virketid pga. raskere metabolisme (tab 1).

Vekuronium ble skilt ut via både leveren og nyrene (pankuronium i praksis bare via nyrene), mens atrakurium hadde en unik organuavhengig metabolisme (esteraser, Hoffmanns eliminasjon). Atrakurium var histaminfrigjørende og kunne derfor i gitte situasjoner gi alvorlig blodtrykksfall. I 1990årene ble derfor stoffet erstattet med cisatrakurium (en av de ti isomerene som atraku- rium består av), et medikament som i dag nyter stor popularitet pga. sin organuavhengige metabolisme. Omtrent samtidig med cisatrakurium ble rokuronium lansert, et steroidmuskelrelaksantium med en anslagstid etter høye doser som kan sammenliknes med den for suksametonium. Kombinasjonen av relativt kort virketid og rask anslagstid har gjort preparatet til den mest brukte muskelrelaksans på verdensbasis i dag.

\section{Er muskelrelakserende midler trygge?}

Omtrent 60 års erfaring har gitt oss god oversikt over fordeler og ulemper ved bruk av muskelrelakserende midler. Suksametonium forsvarer fortsatt sin plass i vårt armamentarium pga. svært rask anslagstid (30-40 sek). Imidlertid begrenses bruken av medikamentet av mange mulige alvorlige bivirkninger, f.eks. hyperkalemi, hjertearytmier og allergisk sjokk (3). Det skal derfor foreligge en klar indikasjon for å bruke medikamentet (behov for svært rask muskelrelaksasjon i øyeblikkelig hjelp-situasjoner). I over $90 \%$ av tilfellene hvor muskelrelakserende midler blir brukt, anvendes derfor et ikke-depolariserende preparat. Også slike midler har bivirkninger, men langt færre og mindre alvorlige enn bivirkningene ved suksametonium.

\section{Endring av muskelrelakserende midlers effekt under anestesien}

Fysiologiske forandringer i forbindelse med kirurgiske inngrep vil kunne påvirke effekten av curaremidler. For eksempel vil en reduksjon i kroppstemperatur fra $36{ }^{\circ} \mathrm{C}$ til $34{ }^{\circ} \mathrm{C}$ doble virketiden for vekuronium fra ca. 30 minutter til ca. 60 minutter (11). Dette er en vesentlig grunn til at man anbefaler monitorering av effekten av muskelrelakserende midler.

Tabell 1 Oversikt over omtalte muskelrelakserende midler. Tidspunkt for introduksjon, hvorvidt medikamentet fortsatt er i bruk, gjennomsnittlig anslagstid (sek) og virketid (min) etter injeksjon av en standard intubasjonsdose (som normalt relakserer diafragma) og hvordan medikamentene elimineres

\begin{tabular}{|c|c|c|c|c|c|c|}
\hline Navn (salgsnavn) & $\begin{array}{l}\text { Type me- } \\
\text { dikament }\end{array}$ & $\begin{array}{l}\text { Introduk- } \\
\text { sjonsår }\end{array}$ & $\begin{array}{l}\text { I bruk } \\
\text { i dag }\end{array}$ & $\begin{array}{l}\text { Anslagstid } \\
\text { (sek) }\end{array}$ & $\begin{array}{l}\text { Virketid } \\
\text { (min) }\end{array}$ & Eliminasjon \\
\hline $\begin{array}{l}\text { d-tubokurarin } \\
\text { (Intocostrin) }\end{array}$ & Isokinolin & 1942 & Nei & 180 & 90 & Nyre, (lever) \\
\hline $\begin{array}{l}\text { Suksametonium } \\
\text { (Curacit) }\end{array}$ & $\begin{array}{l}\text { Diacetyl- } \\
\text { kolin }\end{array}$ & 1950 & $\mathrm{Ja}$ & 45 & 10 & $\begin{array}{l}\text { Plasmakolin- } \\
\text { esterase }\end{array}$ \\
\hline $\begin{array}{l}\text { Pankuronium } \\
\text { (Pavulon) }\end{array}$ & Steroid & 1967 & Nei & 240 & 90 & Nyre, (lever) \\
\hline $\begin{array}{l}\text { Vekuronium } \\
\text { (Norcuron) }\end{array}$ & Steroid & 1980 & $\mathrm{Ja}$ & 120 & 30 & Nyre, lever \\
\hline $\begin{array}{l}\text { Atrakurium } \\
\text { (Tracrium) }\end{array}$ & Isokinolin & 1981 & Nei & 180 & 30 & Organuavhengig \\
\hline $\begin{array}{l}\text { Mivakurium } \\
\text { (Mivacron) }\end{array}$ & Isokinolin & 1988 & Ja & 150 & 20 & $\begin{array}{l}\text { Plasmakolin- } \\
\text { esterase }\end{array}$ \\
\hline $\begin{array}{l}\text { Rokuronium } \\
\text { (Esmeron) }\end{array}$ & Steroid & 1989 & $\mathrm{Ja}$ & 75 & 30 & Lever, (nyre) \\
\hline $\begin{array}{l}\text { Cisatrakurium } \\
\text { (Nimbex) }\end{array}$ & Isokinolin & 1995 & $\mathrm{Ja}$ & 180 & 45 & Organuavhengig \\
\hline
\end{tabular}

\section{Våkenhet under anestesi (awareness)}

Ved iatrogen stopp i tilførselen av anestetika under et kirurgisk inngrep kan teoretisk kurariserte pasienter være våkne uten å være $\mathrm{i}$ stand til å gi signal om dette ved f.eks. avvergebevegelser. I dag er alvorlig grad av våkenhet heldigvis svært sjeldent forekommende $(<0,2 \%)(12)$. Den lave insidensen skyldes flere forhold, først og fremst en rivende utvikling innen metoder for anestesiovervåking (kontinuerlig måling av inhalasjonsgasskonsentrasjon, perifer nervestimulering for å overvåke nivået av muskelblokade, alarmer ved infusjonspumpesvikt, søvndybdemonitorering). Det er også blitt vanlig klinisk praksis å titrere tilførselen av muskelrelakserende midler etter kirurgens behov. Fordi dagens moderne anestesimidler i seg selv gir noe muskelrelaksasjon, kan man ofte redusere tilførselen av muskelrelakserende middel så mye at eventuelle forsøk på avvergereaksjoner som tegn på oppvåkning fra pasientens side kan observeres.

\section{Restkurarisering}

Postoperative resteffekter av medikamenter brukt under anestesi er vanskelig å unngå, og dels er de også ønsket (f.eks. noe opioidanalgetisk effekt). Hvor mye resteffekter etter muskelrelakserende midler (restkurarisering) som er klinisk akseptabelt, har vært diskutert i mange år. Sentrale temaer i denne sammenheng har vært korrekt bruk av antidoten neostigmin (som begrenser nedbrytningen av acetylkolin), fordi det har dårlig effekt ved dyp muskelblokade, og hvorvidt spesielt utstyr for overvåking av curareeffekt kan være til nytte (13). Det har vært en fremherskende oppfatning at selv minimal restkurarisering er ugunstig for pasienten, men få har klart å vise dette i utfallsstudier (14).

Særlig har man vært opptatt av en mulig sammenheng mellom restkurarisering og utvikling av lungekomplikasjoner (15), ikke minst fordi svelgefunksjonen er svært følsom for effekten av muskelrelakserende midler (16). Samtlige langtidsvirkende stoffer er nå avregistrert (tab 1), særlig pga. større mulighet for restkurarisering (17). Høsten 2008 ble en ny type antidot (sugammadex) mot effekten av rokuronium og vekuronium lansert. Den består av et hult sukkermolekyl (et modifisert cyklodekstrin) som i løpet av et par minutter etter administrering er i stand til å inaktivere det som måtte befinne seg $\mathrm{i}$ blodbanen av disse to muskelrelakserende midlene. Anticurareeffekten er dramatisk bedre enn for neostigmin, og man har heller ikke sett vesentlige bivirkninger i forsøk gjort på mennesker. Dessverre har antidoten ingen effekt på curarestoffer av isokinolintypen. Medikamentet er foreløpig for dyrt til å bli brukt rutinemessig.

\section{Allergisk sjokk}

En av de mest fryktede komplikasjonene til anestesi er utvikling av allergisk sjokk. Insidensen er usikker, men den antas å ligge 
mellom 1:10000 og 1:20000 anestesier (18). I to tredeler av tilfellene er sannsynligvis muskelrelakserende midler årsaken, og mekanismen bak reaksjonen er trolig knyttet til nitrogenatomene på muskelrelaksansmolekylet (19). I Norge har frekvensen av allergisk sjokk i forbindelse med anestesi vært langt høyere enn $i$ land vi bør sammenlikne oss med, f.eks. Sverige. Dette henger sammen med at en relativt stor andel av den norske befolkningen sammenliknet med den svenske har antistoffer mot morfin og morfinderivater som kan kryssreagere med muskelrelakserende midler. Det er mulig at dette fenomenet henger sammen med en tidligere ganske fri bruk i Norge av hostemedisin som inneholder folkodein (20). I Sverige har dette medikamentet aldri vært i bruk.

I løpet av siste halvpart av 1990-årene ble det her i landet rapportert mange allergiske reaksjoner i forbindelse med bruk av rokuronium. Selv om midlet på verdensbasis har en betydelig markedsandel, anvendes det derfor lite i vårt land. Foreløpig har vi dessverre ingen god preoperativ metodikk som kan brukes for å identifisere individer som er disponert for allergisk sjokk under anestesi.

\section{Konklusjon}

Muskelrelakserende midler inngår som en integrert og ofte svært viktig del av moderne anestesipraksis. Det forskes fortsatt for å utvikle nye og eventuelt bedre stoffer enn dem vi har til rådighet i dag. Det er uvisst om bruken av disse midlene i Norge vil endre seg etter innføringen av den meget effektive antidoten sugammadex.

Oppgitte interessekonflikter: Tom Heier har fått dekket reiseutgifter til kongresser, har mottatt honorar for konsulentvirksomhet og møteledelse og har fătt godtgjørelse øremerket til forskning for arbeid som hovedutprøver av et nytt legemiddel (sugammadex) av legemiddelfirmaet Schering-Plough. Schering-Plough markedsfører bl.a. curaremidlene vekuronium og rokuronium, som er omtalt i denne artikkelen.

\section{Litteratur}

1. Del Castillo J, Katz B. The study of curare action with an electrical micro method. Proc R Soc Lond B Biol Sci 1957. 146: 339-56.

2. Paton WD, Waud DR. The margin of safety of neuromuscular transmission. J Physiol 1967; 191: 59-90.

3. Durant N, Katz R. Suxamethonium. Br J Anaesth 1982: 54: 195-208.

4. Brodie B. Further experiments and observations on the action of poisons on the animal system. Philos Trans R Soc Lond 1812; 1: 205-27.

5. Bernard C. Action de curare et de la nicotine sur le système nerveux et sur le système musculaire. Comptes Rendus de la Société de Biologie 1850: 2: $195-220$.

6. Dale HH, Feldberg W, Vogt M. Release of acetylcholine at voluntary motor nerve endings. J Physiol 1936; 86: 353-80

7. King H. Curare alkaloids, I. Tubocurarine. J Chem Soc 1935; 57: 1381-9.

8. Griffith $\mathrm{H}$, Johnson $\mathrm{G}$. The use of curare in general anesthesia. Anesthesiology 1942; 3: 418-20.

9. Beecher HK, Todd DP. A study of the deaths associated with anesthesia and surgery: based on a study of 599,548 anesthesias in ten institutions 1948-1952, inclusive. Ann Surg 1954; 140: 2-35.

10. Whitacre R, Fisher A: Clinical observations on the use of curare in anesthesia. Anesthesiology 1945; 6: $124-130$.
11. Heier T, Caldwell JE, Sessler Dl et al. Mild intraoperative hypothermia increases duration of action and spontaneous recovery of vecuronium blockade during nitrous oxide-isoflurane anesthesia in humans. Anesthesiology 1991: 74: 815-9.

12. Sandin RH, Enlund G, Samuelsson P et al. Awareness during anaesthesia: a prospective case study. Lancet 2000; 355: 707-11.

13. Kopman AF. Surrogate endpoints and neuromuscular recovery. Anesthesiology 1997; 87 1029-31.

14. Kopman AF: Undetected residual neuromuscular block has consequences. Anesthesiology 2008; 109: 363-4.

15. Murphy GS, Szokol JW, Marymont JH et al. Intraoperative acceleromyographic monitoring reduces the risk of residual neuromuscular blockade and adverse respiratory events in the postanesthesia care unit. Anesthesiology 2008; 109: 389-98.

16. Eriksson LI, Sundman E, Olsson R et al. Functional assessment of the pharynx at rest and during swallowing in partially paralyzed humans: simultaneous videomanometry and mechanomyography of awake human volunteers. Anesthesiology 1997. 87: $1035-43$

17. Caldwell JE. The problem with long-acting muscle relaxants? They cost more! Anesth Analg 1997; 85 473-5.

18. Mertes PM, Laxenaire MC. Allergic reactions occurring during anaesthesia. Eur J Anaesthesiol 2002; 19: 240-62

19. Moneret-Vautrin DA, Gueant JL, Kamel L et al. Anaphylaxis to muscle relaxants: cross-sensitivity studied by radioimmunoassays compared to intradermal tests in 34 cases. J Allergy Clin Immunol 1988; 82: 745-52

20. Florvaag $\mathrm{E}$, Johansson SG, Oman $\mathrm{H}$ et al. Pholcodine stimulates a dramatic increase of $\lg E$ in $\lg E$ sensitized individuals. A pilot study. Allergy 2006; 61: 49-55.

Manuskriptet ble mottatt 30.9. 2008 og godkjent 2.4. 2009. Medisinsk redaktør Michael Bretthauer. 